\title{
Hot Rolling and Ageing Effect on the Pseudoelasticity Behaviour of Ti-Rich TiNi Shape Memory Alloy
}

\author{
Narendranath. S. ${ }^{1}$, Vijay Desai ${ }^{1}$, S. Basavarajappa ${ }^{2} *$ K.V. Arun ${ }^{3}$, S. Manjunath Yadav ${ }^{2}$ \\ ${ }^{1}$ Department of Mechanical Engineering, National Institute of Technology, Srinivasanagar, \\ Surathkal, Karnataka, India \\ ${ }^{2}$ Department of Studies in Mechanical Engineering, University B D T College of \\ Engineering, Davanagere-577 004 India \\ ${ }^{3}$ Department of Studies in I \& P Engineering, University B D T College of Engineering, \\ Davanagere-577 004 India \\ * Corresponding Author: basavarajappas@yahoo.com
}

\begin{abstract}
This paper presents the findings of an experimental study of how ageing temperature affects the pseudoelasticity (PE) and its phases of Shape Memory Alloy (SMA). These have been examined by means of tensile testing machine and X-ray diffraction (XRD). By increasing the ageing temperature (constant ageing time) from $350^{\circ} \mathrm{C}$ to $550^{\circ} \mathrm{C}$ critical stress for martensite formation and psuedo-elastic elongation increased. However, specimen aged at $650^{\circ} \mathrm{C}$ showed a decrease in the critical stress for martensite formation and psuedo-elastic elongation. After second and third sequence of loading and unloading, the critical stress shifted towards higher side was observed. The XRD measurement revealed that phases present in the matrix drastically changes with ageing temperatures. Transformation was taking place in two-way transformation, i.e., during heating martensite $\left(B_{19}\right)$ transformed to austenite $\left(B_{2}\right)$ while cooling the austenite $\left(B_{2}\right)$ transformed back to martensite $\left.\left(B_{19}\right)^{\prime}\right)$.
\end{abstract}

Key words: Pseudoelasticity; S M A; Critical stress; Elongation

\section{INTRODUCTION}

The development of new materials that can be applied in contemporary engineering structures determines progress in modern technology. The shape memory alloys are the candidate materials for the actuators of smart structures since they have the ability to change properties and are able to function in a controlled response to a change in environment or operating conditions. SMAs 
are the metal alloys that exhibit the special characteristics of either large recoverable strains or large induced internal forces under load and/or temperature changes [1,2]. This ability to fully recover the large inelastic strains is a result of a reversible crystallographic thermoelastic martensite transformation from the austenite/parent phase to the martensite phase or vice-versa. Martensitic transformations involve lattice transformation featuring shear deformation and a coordinated atomic movement, which maintains the one-to-one lattice correspondence between the lattice point in the parent and transformed phases $[3,4]$.

It has been known that SMAs exhibit a large strain beyond the linear elastic range when an external stress is applied in the austenitic state. At the temperature above $A_{f}$ (austenite finish), the extra strain is recoverable almost completely on unloading and as a result, the martensite will transform spontaneously to undeformed austenite upon release of the stress. On the other hand, $\mathrm{SME}$ is one in which the alloy, once deformed at low temperature will stay deformed until heated. The SMAs are heated above the martensite to austenite transformation temperature $A_{s}$ and the martensite to austenite transformation will end at $A_{f}$. This strain recovery phenomenon is called the SME. These two effects in SMAs, which show thermoelastic martensite transformation, have been understood using the self-accommodating mechanism and variant coalescence upon heating. If SMAs encounter any constrain during reverse transformation, they can generate extremely large recovery stresses. This phenomenon provides a unique mechanism for the actuation [5]. So far, quite a few researchers on the transformation of TiNi shape memory alloys have focused on the Ni-rich alloys under the conditions of various compositions, different heat treatments, precipitates, large deformation by tension, thermal cycling, etc [5-10]. However, only a few investigations have been carried out for the Ti-rich alloys [11] and thus further investigations are called for.

In view of the above in the present study, experimental results of thermomechanically treated Tirich $\mathrm{Ti}_{52} \mathrm{Ni}_{48}$ SMAs are presented with discussions

\section{EXPERIMENTAL PROCEDURE}

A Ti-48Ni (at\%) alloy was prepared by tungsten inert gas melting in a water cooled copper crucible having diameter of $24 \mathrm{~cm}$. $100 \mathrm{gms}$ of Ti-48Ni (at \%) was melted and remelted at least six times in a high purity argon atmosphere. The as melted buttons were hot rolled upto $2 \mathrm{~mm}$ thick plates at $850^{\circ} \mathrm{C}$, keeping a constant temperature. The hot rolled plates were homogenized at $850^{\circ} \mathrm{C}$ for $8 \mathrm{hrs}$ in high purity argon atmosphere and subsequently furnace cooled.

These homogenized plates were again aged at $350^{\circ} \mathrm{C}, 450^{\circ} \mathrm{C}, 550^{\circ} \mathrm{C}$ and $650^{\circ} \mathrm{C}$ for $6 \mathrm{hrs}$ in argon atmosphere and subsequently furnace cooled. Specimens for tensile testing were cut by wireEDM. The gauge length of the specimens was $25 \mathrm{~mm}$ long, $5 \mathrm{~mm}$ width and $1.8 \mathrm{~mm}$ thick. Tensile tests were carried out by Hounsfield tensile testing machine. All tests were conducted at room temperature and the strain rate was $4 \times 10^{-4}$ per second. For XRD characterization, samples were carefully cut from these plates with a low speed diamond cutter. The specimens were mirror 
polished manually for X-Ray Diffraction analysis radiation $\mathrm{Co} \mathrm{K} \alpha$ and the scanning angle range chosen for such analysis was $35^{\circ}$ to $120^{\circ}$.

\section{RESULTS}

\subsection{XRD Characterization}

The thermomechanically treated Ti-rich TiNi specimens were scanned over the range of $35^{\circ}$ to $120^{\circ}$ in a Philips X-ray diffractometer. Fig 1 shows the XRD results obtained at room temperature from undeformed specimens. Five specific phases of TiNi were identified. Martensite TiNi (M), austenite TiNi (A), stable secondary $\mathrm{Ti}_{2} \mathrm{Ni}, \mathrm{TiNi}_{3}$ and metastable $\mathrm{Ti}_{3} \mathrm{Ni}_{4}$ were clearly observed. It can be seen from Fig 1 that on increasing the ageing temperature (constant ageing time), the major austenite (A) phase peak base width slowly increases.

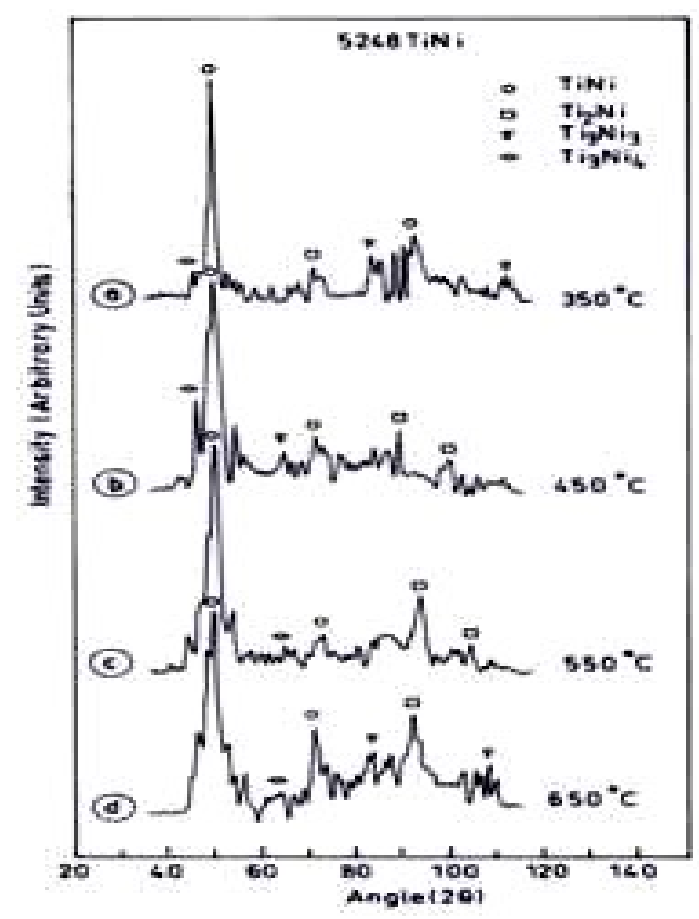

Figure 1. XRD Results of aged $\mathrm{Ti}_{52} \mathrm{Ni}_{48}$.

It can be also seen that martensite (M) peak slowly raises indicating increase in the volume fraction of martensite. New metastable $\mathrm{Ti}_{3} \mathrm{Ni}_{4}$ peak was also observed but in small quantity. At ageing temperatures upto $550^{\circ} \mathrm{C}, \mathrm{Ti}_{3} \mathrm{Ni}_{4}$ peak increased with ageing temperature, where as the volume fraction of $\mathrm{Ti}_{3} \mathrm{Ni}_{4}$ was very small in specimen aged at $650^{\circ} \mathrm{C}$. 
This indicates that some growth of already existing martensite has occurred at the expense of retained high temperature phase [12]. Probably, at different ageing temperatures, this high temperature phase as well as secondary stable phases slowly precipitate in the form of $\mathrm{Ti}_{3} \mathrm{Ni}_{4}$. This locally creates strain zones in the matrix. However, during tensile test (loading and unloading) stress applied on the specimen leads to transformation from martensite to austenite. During unloading partially converted austenite transforms back to martensite.

\subsection{Deformation Behavior}

Upon loading, a fully annealed near-equiatmoic TiNi shape memory alloy may experience an apparent yield via any one of the three processes- martensite reorientation (MR), stress induced martensitic transformation (SIM) and plastic yielding of austenite[13], depending on the testing temperature[14]. For brevity the stress strain curves for tensile tested specimens were aged at $350^{\circ} \mathrm{C}, 450^{\circ} \mathrm{C}$ are shown in Fig 2, the results were same for other two temperatures.

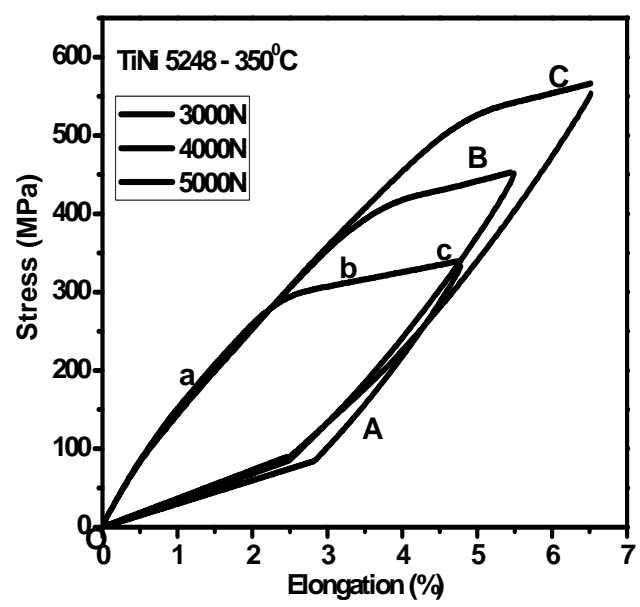

a)

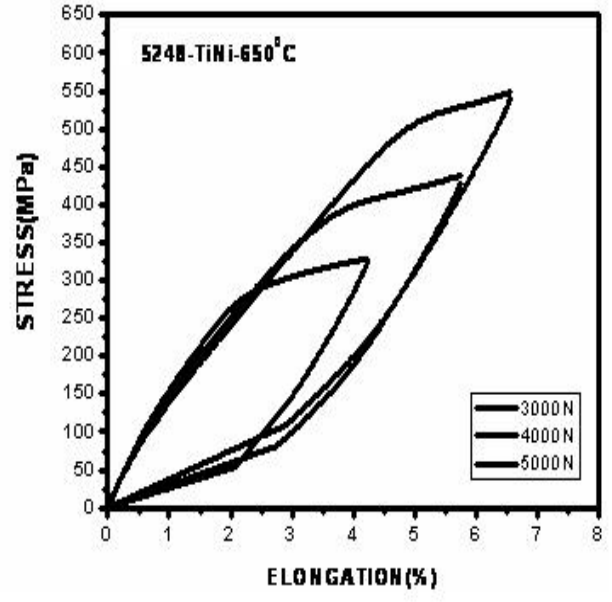

b)

Figure 2. Stress strain curves of $\mathrm{Ti}_{52} \mathrm{Ni}_{48}$ alloy aged at different temperatures.

For each test a virgin specimen was used and a constant strain rate of $4 \times 10^{-4}$ per second was selected. Three loading and unloading cycles were performed on each specimen with $3000 \mathrm{~N}$, $4000 \mathrm{~N}$ and $5000 \mathrm{~N}$ loads. Stress-strain curves of aged TiNi specimens that had undergone three loading and unloading sequences are shown in Fig 2. The first cycle starts and reaches a load of $3000 \mathrm{~N}$ and unloaded was done immediately. Further $4000 \mathrm{~N}$ and $5000 \mathrm{~N}$ cycles were performed without disturbing the set up on the same sample at same strain rate. These curves indicate the work hardening of the specimen as the number of cycles increased. A small amount of residual stress was stored in the matrix. This reveals that, beyond the purely elastic stage (o to a), the curve may be divided into two stages: $a$ to $b$ and $b$ to $c$. The nucleation of the martensite may 
occur by means of the stacking fault mechanism [15] and SIM (stress induced martensite) will appear through the B19 to B2 transformation under deformation below the $\mathrm{M}_{\mathrm{d}}$ temperatures.

Obviously, the deformation behavior during a to b stage (Fig. 2) corresponds to the SIM. However beyond point $b$, both SIM and small amount of plastic deformation leading to residual stress is possibly taking place. This result in permanent change and rise in the stress-strain curve for the next cycle.

The corresponding points $\mathrm{a}, \mathrm{b}$ and $\mathrm{c}$ in the stress strain curve is shown in Figure 2 (a). After points $\mathrm{a}, \mathrm{b}$ and $\mathrm{c}$ are fixed on curve $\mathrm{A}$, the three stages of the stress strain curve can be clearly observed. Projecting points $\mathrm{a}, \mathrm{b}$ and $\mathrm{c}$ to the strain axis produces strain values of $\mathrm{a}^{\prime}, \mathrm{b}^{\prime}$ and $\mathrm{c}^{\prime}$ from which the value of $\eta$ can be calculated,

$$
\eta=\frac{a^{\prime} b^{\prime}}{a^{\prime} c^{\prime}} \quad[16]
$$

where $a^{\prime} b^{\prime}=b^{\prime}-a^{\prime}$ and $a^{\prime} c^{\prime}=c^{\prime}-a^{\prime}$. The value of $\eta$ quantifies the shape memory effect. In Figure 2 (a) curves $\mathrm{B}$ and $\mathrm{C}$ represent second and third loading and unloading sequences.

\section{DISCUSSION}

The effects of ageing after hot rolling on the martensitic phase transformation behavior and mechanical behavior of Ti-rich TiNi shape memory alloys have been discussed.

The effect of ageing on the critical stresses for stress induced martensitic transformation $\left(\sigma^{\mathrm{SIM}}\right)$ is shown in Table 1. Ageing temperature had effect on the $\sigma^{\mathrm{SIM}}$ but not very significant. However, the pseudoelasticity significantly varied with ageing temperature. The phenomenon of TiNi specimens behaving differently in the first thermal transformation cycle after deformation than in subsequent transformation cycle has been observed previously. Lin and $\mathrm{Wu}$ [17], reported that the critical temperature for the reverse transformation in a specimen deformed by $5 \%$ in rolling was increased by $28 \mathrm{~K}$. These increments in the critical temperature become larger when the amount of cold deformation increases and reaches $68 \mathrm{~K}$ for a deformation of $20 \%$. The increase in the critical temperature for the reverse transformations with increase in ageing temperature is indicative of stabilization effect acting on the deformed martensite.

Two possible mechanisms exist [13] which explains this stabilization effect. Firstly, in a heavily deformed specimen, a certain number of structural defects in particular dislocations have been introduced in the martensite matrix by the deformation. These dislocations are expected to be evolved and arranged in such a way that they match the reorientation of the oriented martensite variants. Therefore upon heating, extra resistance has to be overcome for the reverse transformation to proceed, resulting in an increase in the critical temperature for the reverse transformation. Once the oriented martensite has been forced to revert back to austenite, the stabilization effect vanishes in subsequent thermal cycles in which a different, selfaccommodating martensite is formed. However, the dislocations created by the deformation remain in the matrix and this is expected to cause some relatively minor changes in the 
transformation behavior. Secondly, at low levels of deformation, the changes in the dislocation structure caused by the deformation are negligible. In this case, the martensite stabilization effect can only relate to changes in variant accommodation morphologies.

Table 1. Martensite start stress and elongation results for different loads of TiNi

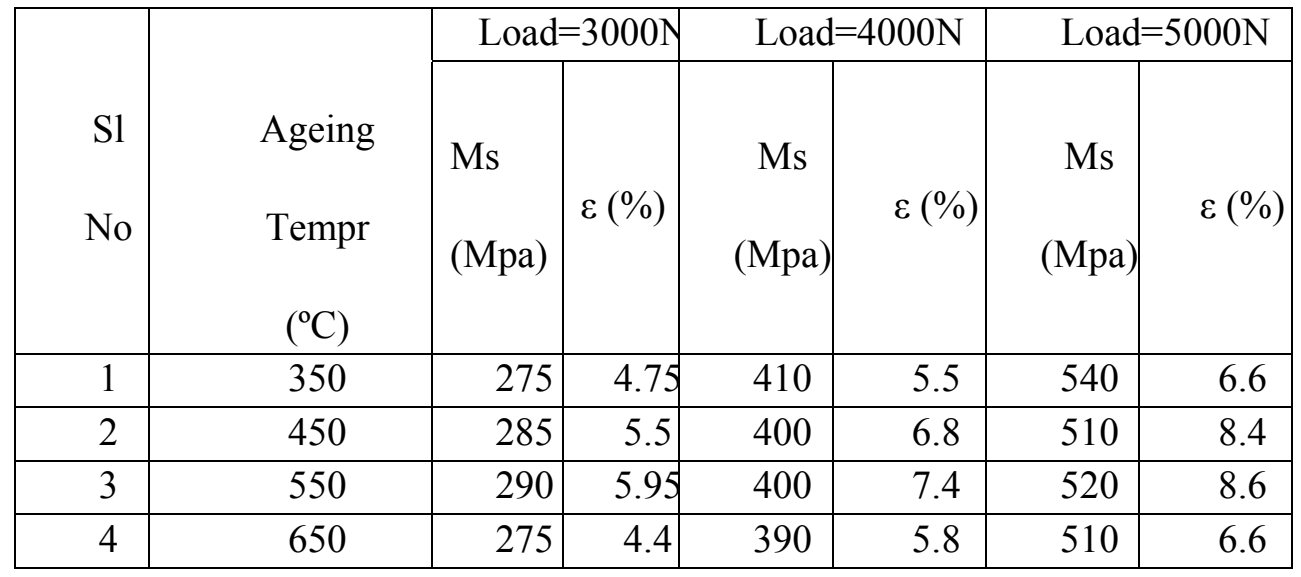

In the present study martensite is getting more and more stabilized with each deformation cycle by the mechanism array of dislocation exerting back stress or internal elastic energy which has to be overcome by more applied stress with each cycle the dislocation density is increasing and thus the martensite stabilization. The near identical psudeo-elastic behavior indicates that permanent changes to the matrix are negligible. The stabilization effect in this case is attributed with the change in the internal elastic energy [13] associated with the change in the structure of martensite.

A minimum stress, $\sigma^{\mathrm{SIM}}$ is recognized to exist for the stress-induced martensitic transformations at $\mathrm{M}_{\mathrm{s}}$. This stress is attributed to the mechanical resistance to phase boundary movement during the stress induced martensitic transformation, since the thermodynamic resistance to the A to $\mathrm{M}$ transformation at this temperature is expected to be practically nil. This stress is believed to originate from the same source as the resistance to twin boundary movement during martensite reorientation and to be dependent on the history of thermomechanical treatment of a specimen. This expectation agrees with the experimental observation that $\sigma^{\mathrm{SIM}}$ increased with increasing ageing temperatures. The reason for the increase in $\sigma^{\mathrm{SIM}}$ with ageing temperature with in the range of $350^{\circ} \mathrm{C}$ to $550^{\circ} \mathrm{C}$ for $3000 \mathrm{~N}$ loading cycle. Probably, for the lower ageing temperature, austenite phase was more in the matrix than compared to $650^{\circ} \mathrm{C}$ aged specimen, as confirmed by XRD results of Fig. 1.

The observed maximum transformation strains, which were measured for first, second, and third loading and unloading cycles are shown in Table 1. The large difference between them also corresponds well to the large difference between the lattice distortions for both transformations. However, the temperature dependence of the transformation strains for both stages is very 
different from each other. The strain associated with the stress-induced martensitic transformation $\varepsilon_{\mathrm{m}}$ increases with increasing ageing temperature $\left(350^{\circ} \mathrm{C}-550^{\circ} \mathrm{C}\right)$, while the strain associated with the $650^{\circ} \mathrm{C}$ aged specimen $\varepsilon_{\mathrm{m}}$ decreases as shown in Table 1 . Therefore, the temperature dependence of the former strain does not reflect the lattice distortion for the martensitic transformation, while the latter strain reflects well the lattice distortion for the Mphase transition [18].

Ageing after solution treatment or ageing at temperatures below recrystallization temperature immediately after hot work produces precipitates and/or dislocations which suppress the martensitic transformation by forming back stress around them against transformation. The amount of the back stress strongly depends on the amount of strain formed by a transformation. The transformation strain associated with the martensitic transformation is about ten times larger than that associated with R-phase transition. Therefore, the Ms point is depressed by the precipitates and/or dislocations [18]. From XRD results Fig 1 we can confirm the presence of $\mathrm{Ti}_{3} \mathrm{Ni}_{4}$ secondary precipitate although the peak intensity was very small.

Hot rolling processing and ageing effect of the shape memory alloys are important for the use of SMAs in engineering applications. In some situations, more recoverable pseudoelastic transformation strain may be needed to achieve better displacement control and some times larger energy absorbability is needed for SMAs to passively reduce vibration. Therefore, the evaluation of the behavior of the hot rolled SMAs, such as pseudoelastic strain, transformation temperatures for loading and unloading cycles is necessary. The hot rolling analysis and mechanical testing can guide the user to control the microstructure of the material and optimal use the SMAs according to the practical applications.

\section{CONCLUSIONS}

The martensitic phase transformation behavior and mechanical properties has been studied by using XRD and tensile tests at room temperature in Ti-rich $\mathrm{Ti}_{52} \mathrm{Ni}_{48}$ shape memory alloys subjected to different ageing temperature treatments consequently the following results were obtained.

- A minimum stress is required to induce martensitic transformation at Ms. This stress is attributed to the mechanical resistance of phase boundary movement during the transformation and is belived to be related to the critical stress for martensite reorientation. This stress is dependent on the metallurgical conditions of an alloy.

- The stress-induced martensite is observed to be more stable relative to the thermal martensite. This stabilization effect is believed to be associated with the change in variant accommodation morphology from self-accommodation for thermal martensite to the oriented state of the stress-induced martensite. The same stabilization effect is also expected for martensite deformed by a reorientation process. 
- The psuedoelastic strain associated with stress induced martensitic transformation $\varepsilon_{M}$ increases with increasing ageing temperature $\left(350^{\circ} \mathrm{C}-550^{\circ} \mathrm{C}\right)$. This is due to increase in $\mathrm{Ti}_{3} \mathrm{Ni}_{4}$ and thus the lattice distortions. With increase in temperature. During $650^{\circ} \mathrm{C}$ ageing, precipitate of $\mathrm{Ti}_{3} \mathrm{Ni}_{4}$ is relatively low leading to decrease in psuedo-elasticity.

\section{REFERENCES}

1. Birman, V., 1997, "Review of mechanics of shape memory alloy structures." Appl.Mech.Review, Vol. 50, pp. 629-645.

2. Otsuka, K. and Wayman, C.M. , Editors, 1998, Shape Memory Materials, Cambridge University Press, Cambridge.

3. Funakubo, H., (ed.), translated by Kennedy, J.B., 1984, Shape Memory Alloys, Gordon and Breach, New York.

4. Liang, C., Rogers, C.A., 1993, "Design of Shape Memory Alloy Springs With Applications in Vibration Control.' J. Vibration Acoustics, vol. 115, pp. 132-135.

5. Nishida, M. , Honma, T. , 1984, “ All-round shape memory effect in Ni-rich TiNi alloys generated by constrained aging." Scripta Metallurgica, Vol. 18, Issue 11, pp. 1293-1298.

6. Wayman, C.M. , 1989, In: Proc. MRS Int.Meet. Adv. Materials (Rich, E.E. and Wilson, C.H., Eds.) 9, pp. 63.

7. Miyazaki, S., Igo, Y., Otsuka, K., 1986, "Effect of thermal cycling on the transformation temperatures of Ti---Ni alloys.'” Acta Metallurgica, Vol.34, Issue 10, pp. 2045-2051

8. Stachowiak, G.B., Mccornick, P.G., 1988, "Shape memory behaviour associated with the R and martensitic transformations in a NiTi alloy." Acta Metallurgica, Vol. 36, Issue 2, pp. 291-297

9. Cai, W. , Musakami, Y. , Otasuka, K. , 1999, "Study of R-phase transformation in a Ti50.7 at\% Ni alloy by in-situ transmission electron microscopy observations." Materials Science and Engineering A, Vol. 273-275, pp. 186-189

10. Tang, W. , Sandstrom, R. , 1993, “ Analysis of the influence of cycling on TiNi shape memory alloy properties.' Materials \& Design, Vol.14, Issue 2, pp. 103-113.

11. Pelosin, V., Riviere, A. , 1998, "Effect of thermal cycling on the R-phase and martensitic transformations in a Ti-rich NiTi alloy.' Metallurgical Transactions A, Vol. 29, Issue 4, pp. $1175-1180$

12. Mohamed, H.A., Washburn, J. , 1977, “ 'Deformation behaviour and shape memory effect of near equi-atomic NiTi alloy." Jr of Material Science ,Vol. 12, Issue 3, pp. 469-480.

13. Yinong Liu, Galvin, S.P. , 1997, “ Criteria for pseudoelasticity in near-equiatomic NiTi shape memory alloys.” Acta Materialia, Vol. 45, Issue 11, pp. 4431-4439.

14. Yinong Liu, Mccormick, P.G., 1989, "Influence of Heat Treatment on the Mechanical Behaviour of a NiTi Alloy.' ISIJ International, Vol.29, Issue 5, pp.417-422.

15. Hsu, T.Y., 1980, "Thermodynamics of martensitic transformation $\beta(Y) \rightarrow \varepsilon . " \quad$ Acta Meatll. Sinica,vol. 16,pp. 430. 
16. Jihua Zhang, Shuchuan Chan, Lei Li, Hsu, T.Y., 1998, “Analysis of the Stress-Strain Curves of a Fe-Mn-Si Shape Memory Alloy.” Materials Characterization, Vol. 40, Issue 1, pp. 37 41

17. Lin ,H.C., Wu, S.K., 1993, “ DDetermination of Heat of Transformation in a Cold-Rolled Martensitic TiNi Alloy.' Metallurgical Transactions A, Vol. 24 A, pp. 293-299.

18. Miyazaki, S. , Otsuka, K. , 1986, “ Deformation and transition behavior associated with the R-phase in TiNi alloys.' Metallurgical Transactions A, Vol. 17 A, pp. 53- 63. 